\title{
Recent Thymic Emigrant
}

National Cancer Institute

\section{Source}

National Cancer Institute. Recent Thymic Emigrant. NCI Thesaurus. Code C112039.

A T-lymphocyte that has completed intrathymic development and has exited the thymus.

These cells are the youngest peripheral T-lymphocytes and migrate to secondary

lymphoid organs where they slowly mature to become naive T-cells. 